\section{Economistas e política: trajetórias na América}

\section{Economists and politics: paths in Latin America}

MONTECINOS, Verónica \& MARKOFF, John (orgs.). Economistas en las Américas: profesión, ideologia y poder politico. Santiago, Ediciones Diego Portales, 2016. 522 páginas.

\section{Vera Alves Cepêda}

Docente e pesquisadora dos programas de pósgraduação em Ciência Política (PPGPol) e Sociologia

(PPGS) da Universidade Federal de São Carlos (UFSCar), São Carlos - SP, Brasil. E-mail: veracepeda@ufscar.br

DOI: $10.1590 / 339714 / 2018$

Chegou recentemente ao Brasil a edição em espanhol do livro Economistas en las Américas: profesión, ideologia y poder politico, organizado por John Markoff (Pittsburgh University) e Verónica Montecinos (Pennsylvania State University). Trata-se de uma coletânea de trabalhos abrangendo a intersecção entre a formação e os efeitos políticos da ação dos economistas no contexto latino-americano. Em cada um dos sete capítulos que compóem a obra, o papel e o protagonismo assumidos pela questão econômica e pela atuação dos economistas são discutidos por um reconhecido especialista: Glen Biglaiser escreve sobre a Argentina; sobre o Brasil, Maria Rita Loureiro; sobre o Chile, Verónica Montecinos; a Colômbia é abordada por Luiz Bernardo Flórez Enciso; o México, por Sarah Babb; Adolfo Garcé discute o Uruguai e, por fim, os Estados Unidos é analisado por Marion Fourcade. Além dos estudos aplicados aos contextos nacionais, o livro conta ainda com um capítulo inicial e um epílogo caracterizados por um esforço intelectual vigoroso de mapeamento e análise das mudanças ocorridas na formação dos economistas, momentos e variaçóes de suas filiaçôes teóricas e em sua maior ou menor presença no esquema decisório das políticas nacionais.

No projeto coletivo de investigação, chama atenção a diversidade das áreas acadêmicas de origem dos pesquisadores, agregando economistas, sociólogos, cientistas políticos e historiadores da democracia. Essa combinação não é acidental. Pelo contrário. Ela é expressão do viés multidisciplinar utilizado para tratamento do objeto em tela nos estudos, pautado no reconhecimento dos nexos profundos e inextricáveis entre o ambiente econômico e o ambiente político. Tal articulação decorre do amplo portfólio derivado da relaçáo entre os problemas econômicos e os seus efeitos no campo da política, tais como a formulação de políticas macroeconômicas, as diretrizes, papéis e funçóes atribuídas às políticas públicas, bem como a definição de projetos políticos de alcance nacional.

Embora ao se falar de "economistas" estejamos nos referindo especificamente a uma comunidade epistêmica, alicerçada sobre uma formação acadêmica e profissional específica, incluindo as possíveis e esperadas filiaçóes a teorias concorrentes e também ao desenvolvimento de uma racionalidade técnica autônoma do campo, é necessário entender a existência do movimento histórico que moldou essa configuração. No caso latino-americano, trata-se da experiência de estreitamento entre as questôes econômicas e as decisões políticas que aumentou sensivelmente o peso e a presença dos economistas, possibilitando-lhes operar a partir da posse de um capital simbólico valiosíssimo (isto é, teses e teorias) para o período e a situação histórica. Como aponta Loureiro, nessa conjunção, é importante assinalar que essa elite "no se identifica y legitima através de los partidos o de la representación electoral, sino por su competencia técnica y cientifica”, e que tal conformação de uma elite intelectual e profissional estratégica teve uma rota ascendente, ao longo do século passado, notadamente nos países da América Latina.

Em seu conjunto, o livro é composto de trabalhos que utilizam a perspectiva histórico-comparativa para a análise das trajetórias nacionais, trazendo um rico e dinâmico panorama da intersecção entre a economia e a política, em especial, a partir da atuação concreta dos economistas em cargos de poder. Os estudos encontrados em Economistas en las Américas pretendem examinar de maneira retrospectiva dois grandes problemas. Por um lado, as análises abordam as condiçôes específicas da emergência da conexão entre a economia e o poder estatal - situação que origina o status de elite política dos economistas e reforça a sua influência. De outro lado, os pesquisadores observam as instituições acadêmicas, as arenas governa- 
mentais ou profissionais nas disputas por predomínio nos campos teóricos da economia e os seus efeitos nos ambientes decisórios. Esse processo é analisado mediante o cenário de cada país e mobilizado por vários temas como a modernização, os obstáculos econômicos, o papel do Estado, as respostas às demandas sociais e as configuraçôes de regimes políticos. Basta lembrar que encontramos na história política latino-americana múltiplas combinaçóes entre regimes autoritários modernizadores ou de defesa de projetos tradicionais, democracias modernizadoras ou populistas, bem como alianças entre burocracia e autoritarismo. Nesses contextos, a questão econômica, em especial o tema da superação do subdesenvolvimento, foi elemento importante no arranjo político e nas coalizóes de governo - pesando ainda, nesse quadro, as pressóes externas e os constrangimentos geopolíticos mundiais. Percebe-se, com efeito, o desafio e a complexidade da proposta de pesquisa, resultando em um rico acervo de informaçóes sobre as experiências latino-americanas e, nelas, a precedência do debate econômico sobre as escolhas políticas.

O ponto irradiador da agenda de pesquisa da coletânea foi a guinada neoliberal que ocorreu na América Latina, em especial, após a década de 1990 - e este ponto é crucial nos estudos, porque revela uma inflexão de trajetória, após a longa persistência do desenvolvimentismo. Além disso, a importância do destaque conferido ao neoliberalismo é a de funcionar como um divisor de águas, oscilando entre o anterior modelo de protagonismo estatal e o modelo recente de valorizaçáo do mercado. No fundo, trata-se de compreender os motivos dessa mutação de sentido que envolve, necessariamente, tanto o reposicionamento da explicação econômica quanto o papel do Estado na orientação da vida econômica e social da região.

Mantendo no horizonte esse cenário, podemos detectar a presença de dois movimentos analíticos ao longo dos capítulos, a partir dos quais os trabalhos se desenvolvem em suas especificidades. O primeiro movimento trata da importância assumida pelas ideias econômicas na configuração dos padróes de modernidade, na função atribuída ao mercado ou ao Estado, na definição do papel e das metas das políticas públicas, bem como a implicação das ideias nos regimes e instituições democráticas na regiāo. Em linhas gerais, é como se afirmássemos que o "pensamento econômico conta” por orientar decisóes importantes em um mundo centrado no trabalho e na esfera da produção, organizando a vida individual, social e os projetos nacionais. Segundo os autores, o crescimento da economia no debate político ocorreu em escala mundial, a partir do Entreguerras e da Crise de 1929, assumindo, na América Latina, uma modulação mais profunda, derivada da forte presença do desenvolvimentismo e da teoria cepalina. O primum mobile desse protagonismo surge da conversão da questão econômica em questão nacional e na identificação das causas do atraso e do déficit de modernidade à distância existente entre a estrutura econômica das sociedades periféricas e a dinâmica e capacidade de autorreprodução das sociedades desenvolvidas. A compreensão do grave perigo que os obstáculos econômicos - desiguais e assimétricos entre o centro dinâmico e a periferia reflexa e dependente - imputariam ao projeto de autonomia nacional dos países nessa situação pode ser encontrada no Manifesto dos Periféricos, espécie de carta fundadora de tal consciência, publicado em 1949, pela Comissão Econômica para a América Latina e o Caribe (CEPAL).

Tomando o caso do Brasil como exemplo, dada a importância que a tese do subdesenvolvimento e o projeto do planejamento (ambos pertinentes ao repertório do estruturalismo cepalino) assumiram no país, o século XX aparece fortemente marcado por oscilaçóes no dilema "mais mercado versus mais Estado”. O ponto inicial dessa tensão pode ser fixado na crise aberta, ao final da Primeira República, em face da defesa dos interesses primário-exportadores (baseados no princípio das vantagens comparativas ricardianas e no livre-comércio -- portanto, livre mercado). No período pós-1930, o enfraquecimento da vocação agrária abriria espaço para o ciclo longo e complexo de planejamento estatal, pautado na centralizaçáo política e nos monopólios promovidos a partir do governo Vargas. Emerge o momento áureo do desenvolvimentismo ancorado na centralidade do planejamento econômico como resposta ao problema de construção de um projeto nacional, mas encontrando dois momentos políticos distintos: o desenvolvimentismo com democracia (décadas de 1950 e primeira me- 
tade da década de 1960) e o desenvolvimentismo autoritário (iniciado com o golpe de 1964).

Ao longo do século XX, enquanto a economia ganhava força como parte da explicação da vida social ou das causas do atraso reforçando sua centralidade explicativa e conformando "un papel cada vez más decisivo a los economistas", ocorria, em simultâneo, um amplo e rápido processo de institucionalização acadêmica promovendo a recepção das grandes teorias internacionais e a adaptaçáo delas ao contexto interno. Dependendo do momento e do projeto político-econômico em voga, essa recepção foi acompanhada de "ressignificação" ou apenas de "assimilação". A ressignificação de postulados ocorreu particularmente no caso da CEPAL com a produção de um corpo teórico autóctone que dialogava com as "grandes teorias gerais", mas as modificava pela exigência de sua aplicação à realidade - como é o caso da feição compósita e heterodoxa assumida pelo estruturalismo historicista cepalino. A assimilação, por sua vez, é exemplar da abordagem teórica que fundamenta a agenda de pesquisa da coletânea aqui resenhada: a adoção acrítica, sem mediações quanto à situação e aos efeitos do receituário neoliberal, no contexto local. Nesse caso, mais do que a circulação e a recepção de teorias, estamos lidando com o problema da dominação hegemônica (a face exitosa da luta entre ideologias). A utilização acrítica do neoliberalismo advém de uma questão que divide o campo dos economistas há mais de um século: sobre a objetividade, neutralidade e universalidade dos postulados econômicos, apresentados em sua abstração teórica, como imunes às diferenças temporais e históricas, às trajetórias e às condiçôes das formações nacionais. Essa percepção clássica, neoclássica e neoliberal reifica o mercado como único e legítimo elemento válido para a fundamentação da expertise econômica, dotando-o de uma racionalidade autônoma. Todavia, os pressupostos e os argumentos de matriz cepalina são opostos aos da matriz neoliberal, o que explica a tensão ideológica e prática entre os dois campos, na América Latina. A institucionalização acadêmica é parte integrante da conexão entre economistas e política. $\mathrm{Na}$ academia, as fronteiras são demarcadas; as teses, as narrativas, as diretrizes da economia são forjadas; aqueles representantes que atuarão nas empresas, no Estado, no debate público e na reprodução do campo, nas próprias instituiçôes acadêmicas, são preparados e legitimados. Não é casual que as pesquisas abrigadas na coletânea tomam a formação, a profissão e as concepçóes teórico-econômicas distintas dos economistas no contexto latino-americano como meios de analisar o modo pelo qual foi produzida e agiu uma elite dotada de robustas capacidades políticas, amparada em conhecimento especializado.

Um segundo movimento ou nível de análise apoia-se no problema da adesão ao padrão "mais mercado" na experiência recente do continente, diretamente ligado ao modelo neoliberal e ao Consenso de Washington. A investigação sobre o impacto e os desdobramentos dessa adesão apontam: o desmanche da rede de proteção social (que, convenhamos, é muito recente e frágil na maioria dos países estudados); o avanço das políticas de privatização, que assume o caráter de transferência e apropriação privada - muitas vezes, por empresas não nacionais - de um amplo estoque do investimento público, o qual é financiado pelo processo social de tributação e pelo endividamento do Estado (parte do compromisso social da etapa desenvolvimentista); o desmantelamento de políticas de proteção e incentivos aos setores industriais ou estratégicos; o enfraquecimento dos mecanismos públicos de regulação; e a fragilização do Estado, como o ator fundamental de articulação e implementação de um projeto de desenvolvimento econômico e de um projeto nacional autônomo e autossustentável.

$\mathrm{Na}$ indagação sobre a incorporação do ideário neoliberal, as pesquisas apontam uma miríade de elementos, mas centralizam a questão em torno dos arranjos intelectuais que implementaram o giro para o padrão "mais Mercado, menos Estado: retira-se o Estado como garantia da vida social e como corretivo das distorçóes do mercado e, em movimento contrário, passa-se a imputar à ação estatal o caráter de fonte de todos os males. A meu ver, essa mutação expressa uma ressignificação estratégica nascida de uma vigorosa rotação no plano das ideias e que adentra e afeta as instituiçóes ou arenas sociopolíticas que as sustentam.

Aceitando-se que a comunidade dos economistas participa e participou, em maior ou menor grau a depender da conjunção histórica, das decisôes sobre os modelos de desenvolvimento e o padrão de políticas públicas no continente, torna-se importante 
saber como e por quais meios a perspectiva neoliberal foi introjetada no grupo dos economistas. No caso recente, a compreensão do "processo de americanização" das ideias econômicas explica-se pelas seguintes açóes: a formação de economistas no exterior, em especial, na pós-graduação; a participação em congressos e conferências referenciadas como as mais importantes na área da Economia; a recepção e a circulação de publicaçóes internacionais; a publicação em veículos internacionais; o desenvolvimento de atividades, mesmo que temporárias, em instituiçóes estrangeiras de pesquisa, governamentais ou privadas; e a assimilação de teorias, literatura, jargóes e métodos, particularmente nos currículos acadêmicos de graduação e pós-graduação. Assim, para entendermos a trajetória do neoliberalismo na América Latina, a "variável” chave adotada como fio condutor dos trabalhos é a formação, a atuação e a ideologia dos economistas de cada caso estudado exatamente o subtítulo adotado no livro: profesión, ideologia y poder político.

A preocupação dos autores, quanto à adoção da narrativa teórica neoliberal e sua racionalidade implícita, indica o reposicionamento da clássica disputa intelectual da América Latina, isto é, a contenda entre os "desenvolvimentistas" (ápice da integração entre economia e política) e os defensores da "mão invisível do mercado" (aparente redução da função social e política atribuída à economia).

Como observaçôes pontuais, confesso que li com muita curiosidade os capítulos sobre os Estados Unidos (EUA) e o Brasil. A incorporação do caso norte-americano em um conjunto de países que, em comum, partilham a situação de "não desenvolvimento avançado" me admirou. Argentina, Brasil, Chile, Colômbia, México e Uruguai comungam a herança do colonialismo, do capitalismo tardio, periférico e primário-exportador, os obstáculos do subdesenvolvimento e o fato de terem sido, em maior ou menor grau, tocados pelas ideias do estruturalismo cepalino. Os EUA, também produto da Expansão Ultramarina, assumiu, como nos diz Celso Furtado, em Teoria e Política do Desenvolvimento Econômico (1971), uma forma mais rápida e eficaz de passagem para a etapa de capitalismo industrial e, embora compartilhasse com seus pares latino-americanos a origem colonial, não demorou a sair da posição de periferia, migrando para o status de economia central. $\mathrm{O}$ interesse no exame da trajetória estadunidense é compreensível dada a sua condição de produtor de hegemonia no campo da teoria econômica e ator importante nos processos de modernização dos demais países do continente. Afinal, a ascendência norte-americana pesou fortemente nas diretrizes e postulados acadêmicos, também no campo dos modelos de desenvolvimento adotados pelos países em sua órbita de influência. As teorias econômicas produzidas nos EUA circunscreveram o processo de industrializaçáo latino-americano. Com efeito, no plano concreto, tais teorias não puderam ser ignoradas, dada a necessidade dos países em desenvolvimento no que diz respeito à parceria internacional no tocante aos investimentos e apoio tecnológico para superação da fase de substituição de importaçóes e impulsão da cadeia industrial, em especial os setores de infraestrutura e de bens de capital. Ao final da Segunda Guerra Mundial e com a emergência da Guerra Fria, a relação dos países do continente americano com os EUA tornou-se mais complicada: houve a ingerência real da política externa norte-americana sobre o continente (vide o projeto da Aliança para o Progresso), bem como o enrijecimento das teses econômicas menos intervencionistas e mais atreladas ao padrão de crescimento via mercado aberto.

É certo que uma forma de influir no padrão do desenvolvimento econômico e nas escolhas políticas seria viabilizada através da incorporação dos pressupostos teóricos neoclássicos pela prestigiosa camada dos economistas e administradores públicos - grupos dotados de capacidade interna de ingerência e orientação dos rumos das políticas econômicas e também dos projetos nacionais. A barreira de entrada ao pensamento econômico norte-americano no período devia-se à forte presença da teoria cepalina, mas tal configuraçáo foi enfraquecendo ao longo do tempo até a crise do padrão nacional-desenvolvimentista, em torno dos anos 1980, e sua substituição pelo modelo neoliberal no continente.

A leitura do capítulo escrito por Marion Fourcade adicionou dois pontos a esse cenário. O primeiro ponto diz respeito ao fato de os EUA concentrarem a "mas extensa e diversa" produção de conhecimento econômico do mundo, sendo uma "economia de economistas", na qual, em raríssimas vezes, os cargos políticos foram ocupados por 
economistas (divergindo, com efeito, da trajetória comum aos países latino-americanos). $\mathrm{O}$ segundo ponto lança luz sobre o fato de que, mesmo nessa situação, as teses econômicas são poderosíssimas, pois são assimiladas como "a" racionalidade eficiente e pela prevalência dos critérios microeconômicos no julgamento e implementação de decisóes - assim "aunque los economistas no gobiernan Estados Unidos la disciplina económica sí lo hace” e o faz através da hegemonia que exerce sobre as políticas públicas. Essa informação é importante para entendermos que a preponderância de um modelo não depende do controle direto dos postos de comandos. Ao contrário, esse controle será tão mais eficiente quanto mais naturalizado e introjetado na forma de uma racionalidade operante.

O caso brasileiro parece servir de exemplo para a recepção dos postulados teórico- econômicos norte-americanos. Em seu estudo, Loureiro retoma essa trajetória desde o processo de centralização política do Estado brasileiro, da formaçáo do aparato e quadros da burocracia pública, do fortalecimento da ação estatal, avançando sobre a construção das carreiras, instituiçôes e lócus de ação dos economistas. A autora destaca, como expressivo do caso brasileiro, a persistência do debate entre os monetaristas e os estruturalistas, cujo contorno foi delineado antes mesmo da criação da CEPAL, com a diatribe entre Roberto Simonsen e Eugênio Gudin, apontando, em outros momentos, para o processo e os projetos de constituição das instituiçóes acadêmicas. No período neoliberal, essa disputa pode ser visualizada na aceleraçáo e no fortalecimento do processo de assimilação dos padrôes teóricos e metodológicos norte-americanos nos cursos de economia no Brasil. A autora analisa algumas das mais expressivas instituiçóes acadêmicas no país, na graduação e na pós-graduação, tais como a Escola de Pós-Graduação em Economia - Fundação Getúlio Vargas (EPGE/ FGV), a Pontifícia Universidade Católica - Rio de Janeiro (PUC/RJ), o Instituto de Pesquisas Econômicas da Universidade de São Paulo (IPE/USP), o Instituto de Economia da Universidade Federal do Rio de Janeiro (IE/UFRJ) e o Instituto de Economia da Universidade Estadual de Campinas (IE/
UNICAMP), com informações sobre a formação de docentes e pesquisadores no exterior, a adoçáa de bibliografia internacional e o volume da publicação de artigos ou livros em língua inglesa. Em programas acadêmicos mais ortodoxos, a taxa de docentes com pós-graduação alcançada em instituições norte-americanas chega a $82,35 \%$, ao passo que, em programas fiéis à tradição heterodoxa e mais progressista, a taxa encontrada é de 92,8\% com formação em cursos de pós-graduação no Brasil. O quadro atual espelha a predominância da vertente neoliberal, muito diverso do cenário do pensamento econômico dos anos de 1950-1960, no qual a hegemonia era dada pela tradição estruturalista e cepalina.

Por último, um desabafo: tentar apresentar o panorama geral de um trabalho com a envergadura de Economistas en las Américas: profesión, ideologia y poder político é uma tarefa hercúlea e complexa. $\mathrm{O}$ amplo leque de casos e de focos de análise, a riqueza de informaçóes sobre a trajetória da relação histórica entre política e economistas na América Latina, somadas à descrição do processo de construção e mudanças nas instituiçóes acadêmicas e nos círculos de atuação dos economistas nos países latino-americanos estudados certamente dificulta a possibilidade de síntese. Assim, nesta resenha, optei pela apresentação do plano da obra e de algumas questôes centrais nela tratadas, destacando, talvez pelo reconhecimento da importância que o tema teve e tem na vida pública brasileira, o problema da correlação entre as escolhas econômicas e sua determinação nos projetos políticos. Mas a enorme massa de informaçóes contidas nas mais de quinhentas páginas do livro permanece à disposição dos leitores para outras interpretaçóes.

\section{BIBLIOGRAFIA}

FURTADO, Celso. (1971), Teoria e politica do desenvolvimento econômico. $4^{\mathrm{a}}$ edição. Sáo Paulo, Editora Nacional. 